\title{
The Role of Audiovisual Mass Media News in Language Learning
}

\author{
Taher Bahrani \\ Department of English, Mahshahr Branch, Islamic Azad University, Mahshahr, Iran \\ Faculty of language and linguistics, University of Malaya, Malaysia \\ Tel: 60-147-117-202Ｅmail: taherbahrani@yahoo.com \\ Tam Shu Sim \\ Faculty of language and linguistics, University of Malaya, Malaysia \\ Tel: 60-379-673-132Ｅmail: tamss@um.edu.my
}

Received: February 22, 2011 Accepted: March 8, 2011 doi:10.5539/elt.v4n2p260

\begin{abstract}
The present paper focuses on the role of audio/visual mass media news in language learning. In this regard, the two important issues regarding the selection and preparation of TV news for language learning are the content of the news and the linguistic difficulty. Content is described as whether the news is specialized or universal. Universal contexts are likely to be more comprehensible than specialized contexts. As for the linguistic difficulty, it consists of acoustic, lexical/syntactic and text-type difficulties. Accordingly, audiovisual texts with greater iconic combinations are likely to be more comprehensible for language learning. Moreover, the present paper provides empirical evidence of the role of exposure to news from mass media on speaking fluency.
\end{abstract}

Keywords: Mass media, News, Selection, Content, Linguistic difficulty

\section{Introduction}

In the last few years, the output of TV news has exploded both in English and non-English speaking countries such as Iran which is an EFL context. For example, in Iran, there are two channels broadcasting English news. One is Press TV which is broadcasted 24 hours 7 days a week in English and IRINN which is broadcasted almost 12 hours in English every day. TV news programming in English is not only a vast language learning resource which provides meaningful opportunities for non-reciprocal listening but a vital and immediate alternative source of information. The pedagogical and informative aspects of news broadcasts in English may therefore often and dramatically intersect.

Although much has already been written about the pedagogical values, selecting and using mass media technologies such as video, film, and CDs in general in the second language classroom (Joiner, 1990; Cooper et al., 1991; Stempleski \& Arcario, 1992; Rubin, 1995), less research has focused on the pedagogical problems of selecting and presenting TV news (Brinton \& Gaskill, 1978; Cooper, 1996; Gruba, 1997; Meinhof, 1998). Regarding the increasing accessibility of TV news in English, this paper focuses on the criteria for selecting TV news stories to be used as a pedagogically valuable material for language learning. This paper mainly aims at the selection criteria for TV news stories.

The two main categories for assessing the pedagogical value of TV news are: a) content and b) the linguistic difficulties.

This research is based upon a course that one of the researchers has taught in current affairs to a group of Iranian EFL students, including both males and females, of intermediate proficiency $(\mathrm{N}=30)$. The proficiency level of the students was determined based on a speaking test from IELTS. Although these students have low self-confidence with regard to their abilities to listen to authentic materials such as TV news, they are very much motivated and have a high degree of interest in this kind of authentic materials. In terms of understanding TV news, factors such as interest and motivation may be more important than linguistic ability for native and non-native speakers alike (Wodak, 1987). The class met 4 hours per week for 3 months in a foreign language context. Moreover, the responsibility for selection of materials was on the teacher.

\section{TV and radio news in language learning}

Exposure to mass media news (for example, TV and radio news), the pedagogical value of such materials, and the possibility of using TV and radio news at all levels of EFL/ESL settings in order to enhance different language skills 
have been the focus of so many studies (Brinton and Gaskill, 1978; Poon, 1992; Baker, 1996; Cauldwell, 1996; Berber, 1997; Cabaj and Nicolic, 2000).

In a research conducted by Brinton and Gaskill (1978), the effect of listening to TV and radio news on improving EFL students' listening comprehension was studied. Brinton and Gaskill (1978) argue that using TV and radio news utterances as teaching material has proved effective on improving listening comprehension of EFL learners having difficulty in dealing with comprehending news utterances. However, Brinton and Gaskil do not mention any thing about the kind of news to be selected. A similar study which focused on using TV news to improve listening proficiency was also conducted by Poon (1992). Poon found out that greater exposure to TV and radio News improves listening comprehension to significant amount. In addition to the above mentioned studies, Baker (1996) also focused on the pedagogical value of TV news in EFL classes and listening comprehension. According to Baker (1996), TV and radio news can help EFL students improve their listening comprehension.

The use of fast speech such as those of TV and radio news in EFL/ESL classrooms has also been studied by some other scholars. In this regard, Cauldwell (1996) conducted a study aiming at discovering the relationship between direct encounters with fast speech such as TV and radio news and teaching listening to EFL students. Accordingly, students may have some problems copping with fast speech at first. However, EFL students can alleviate these problems and improve their listening through great amount of exposure to fast speech. Another short study conducted by Mackenzie (1997) also highlighted the possibility of using TV and radio news reports at all levels of EFL learning. The study rejected the assumption that because the reporters speak too fast, the content is too complex, and the vocabulary is too difficult, TV and radio news cannot be used at lowest levels of EFL situations. Mackenzie's study included some techniques to be used by the teachers while trying to use news in their classes. As the matter of fact, Mackenzie did not say anything about criteria for the selection of news. What he focused on was the use of fast news at all levels with different techniques.

Regarding proficiency and comprehension of television and radio news in a foreign language, a research by Berber (1997) highlighted the point that through enough exposure to these materials, students can easily cope with the comprehension of such materials. Cabaj and Nicolic (2000) also noted that a great amount of exposure to TV and radio news could help students improve their listening comprehension. Moreover, through exposure to TV news and radio programs students acquire the knowledge, structures, strategies, and vocabularies they can use in everyday situations. However, Wetzel et al. (1994), in their study, found that TV news is not always helpful in comprehension.

In short, the majority of the aforementioned descriptive and experimental works have been conducted on the pedagogical value and the effect of exposure to TV and radio news genre on promoting different language skills especially listening comprehension but none of them has specifically focused on the discovering the nature of the news to set a clear criteria for the selection of the news. This is one of the initial reasons to carry out the present study.

\section{Research design}

The research design of this paper focuses on two modes of enquiry. First, it seeks to make explicit the process of material selection by the teacher. This is seen as part of an ongoing process to articulate and represent what teachers know and are learning through their work in the classroom. Second, the paper reflects upon the use of selected materials in the classroom within the framework of action research.

\subsection{Content Schemata}

Research in cognitive science suggests that knowledge is organized in the form of schemata (Rumelhart, 1980). Weaver (1994) defines a schema as an organized knowledge or experience. According to Bell (1991), schemata aid the interpretation of both linguistic and non-linguistic sensory data by providing a context in order to predict meaning and fill in missing information. Exogenous and endogenous contexts are two major issues in relation to content schemata.

Exogenous contexts require prior knowledge. The nature of this prior knowledge may be specialized or universal. Specialized contexts such as Iran, Japan, or Iraq require such massive prior knowledge that even many native speakers may lack the appropriate schemata.

Endogenous contexts, such as news film of a sporting incident or natural disaster, require little or no prior knowledge in that they create their own contexts (although, of course, learners will need the appropriate vocabulary to be able to talk about what they see happening in the video sequence). In other words, the visuals speak for themselves. According to Cooper (1996), episodic news stories are dependent on knowledge of the previous events in the story and 
so put special conditions on comprehension. Similarly non-episodic news items, while not requiring knowledge of a prior story, may still require large amounts of background knowledge.

It is suggested that TV news items with universal exogenous contexts are likely to be the most available and the most accessible to students. However, before such items are used in the classroom their appeal needs to be tested through such devices as questionnaires. And during their presentation their value as newsworthy items in the culture of origin needs to be made explicit. This was actually done in this research and related news episodes were selected based on the participants of this study. As the matter of fact, at the end of each session, the researcher asked the participants about their favorite topic for the next news item to be selected and prepared for them.

\subsection{Linguistic Difficulty}

Linguistic difficulties are defined here under three headings of text characteristics: acoustic, lexis/syntax and text-type (which include both visual and linguistic text):

- Acoustic: The acoustic characteristics of a text include speech-rate, pause phenomena, hesitation, stress and rhythmic patterning.

- Lexis/Syntax: TV news as a whole and news items in particular contain a high degree of redundancy. Redundancy in input is generally understood to aid second language comprehension (Chaudron, 1983; Chiang \& Dunkel, 1992). Chiang \& Dunkel found that repetition of constituents, paraphrase, and synonyms work best with higher levels.

- Text Type:

A. Narrative vs. non-narrative text: Research into native speaker comprehension of TV news suggests that viewers experience substantial comprehension and recall difficulties (Bell, 1991). Stories with a clear narrative story line tend to be processed easier than those without, but for the most part TV news is made up of non-narrative text. In L2 listening comprehension research, Shohamy and Inbar (1991) found that when they compared the relative comprehensibility of three text types: TV news broadcast using a prewritten, edited monologue, and an interactive consultative dialogue, the news item was the most difficult to process. Brown (1995) has shown that narrative texts are easier for L2 learners to listen to and recall than expository texts are, and further, events described in chronological order are easier to recall than narratives with disrupted sequences or flashbacks. This suggests that the general trend of network American TV news towards dramatic framing of news stories, news as "infotainment" and the conversationalization of TV news discourse are likely to have beneficial effects for L2 processing.

B. The union of spoken and visual texts: Perhaps one of the least understood features of TV news broadcasts is the combination of words and pictures which has primacy in the process of decoding. The established semiotic view exemplified by Gruba (1997) is to argue for the dependence of images on verbal text or, to be more exact, the narrowing down of the multiplicity of imagistic interpretations by the spoken text. As Gruba (1997) notes, such a view appears to be rather simplistic. First, distinguishing between what we hear and what we see is not necessarily a difference between words and pictures but a difference in the way we receive the information though our eyes and ears (Meinhof, 1998). Inscriptions, captions, posters, diagrams for example appear on the visual track while the soundtrack may carry background noises and music as well as the spoken text. Second, it may be better to conceive of words and pictures creating a whole message unit rather than separate entities. Certainly, there will be instances when the linguistic text drives the comprehension of the visual input and there will also be instances where the visuals are dominant, but for the most part comprehension will depend on the interaction between the two.

In short, the degree of fit between words and images is a very important factor regarding comprehension.

\section{An experiment of the effect of mass media news on speaking fluency}

\section{Subjects}

The participants of this study were initially two hundred EFL learners including both males and females out of whom 60 participants were selected to carry the research with.

\section{Instruments and materials}

The first instrument was a sample speaking and listening IELTS tests (30 listening questions and a speaking test which was scored out of 30) which was used as a pre-test. The second instrument which was used as a post-test was another sample speaking proficiency test from IELTS. In relation to the pre-test and the post-test, it should be considered that the pre-test included both a listening and a speaking tests. This was because before the experiment 
the homogeneous participants should have had almost the same level of speaking and listening proficiency. On the contrary, the post-test only included a speaking test. This was mainly because after the experiment the focus was only on possible changes regarding speaking fluency.

In order to score the interviews, a checklist developed by Askari (2006) was used (see appendix I). The validity of the checklist had been verified by him suing a pilot study. Regarding the checklist it should be mentioned that it scores each speaking test out of 30. Moreover, it included six scales including fluency, comprehension, communication, vocabulary, structure, and accent. Each scale incorporates five levels (5 points). It should also be mentioned that, to develop the speaking proficiency assessment checklist, various sample checklists including Hughes (2003), Heaton (1990), and Underhill (1987) were reviewed and closely evaluated by Askari (2006).

Regarding the materials that were used, it should be mentioned that two kinds of different materials from the same mass media (TV and radio) were used. The first one was a collection of 150 hours authentic news programs including both video and audio and the second material was a collection of 150 hours authentic programs rather than news.

\section{Procedure}

This research was conducted based on pre-test and post-test design. The first step to take, before the participants were selected, was to verify the reliabilities of the sample listening and speaking IELTS pre-tests. To do so, the tests were given to a group of EFL students including both males and females. Then, the reliabilities of both tests were calculated separately by means of KR-21 formula. Once the reliabilities of the tests were verified, they were given to the two hundred initial participants. When the scores of the tests were obtained, the average mean of the scores (out of 30; speaking 30 and listening 30) were calculated and 60 participants who scored one standard deviation above and below the mean were selected as homogeneous language learners and divided into two groups as group one $(\mathrm{n}=30)$ and group two $(\mathrm{n}=30)$ based on random judgment sampling.

Regarding the speaking test, it should be mentioned that each interview was scored out of 30 according to the speaking proficiency scale which includes six scales of fluency, comprehension, communication, vocabulary, structure, and accent and each scale incorporated five levels (5 points).

More importantly, in order to increase the reliability of the speaking scores, rating activities were carried out first by the researcher himself and then by an inter-rater and later the mean score of speaking pre-post tests for every participant was calculated. Moreover, only the speaking fluency score of each of the 60 participants in the pre-test were used later to be compared with the speaking fluency score which were obtained by each participant in the post-test.

Throughout the experiment which lasted for one year (3 hours a week), the researcher provided group one with the news media exposure (from the above mentioned 150 hour collection) to work on in- and out-side the classroom with researcher monitoring. On the contrary, group two was provided with exposure to non-news programs (from the above mentioned 150 hour collection) to work on in- and out-side the classroom with researcher monitoring.

During the experiment and for each interval between every two sessions, group one was asked to watch and listen to at least 4 hours of the already selected news from the collection from mass media outside the classroom and write down the summary of whatever was heard which was viewed and discussed later inside the classroom. Moreover, group two was also asked to do the same with non-news media programs outside the classroom. As the matter of fact, this was only done to make sure that group one had at least the same minimum amount of exposure to news from the mass media and group two had at least the same minimum amount of exposure to non-news programs from the mass media outside the classroom.

After one year of exposure, all the participants took a same sample speaking proficiency test from IELTS as a post-test to check if there was any change in their speaking fluency. After the participants were given the speaking post-test, only the speaking fluency scores of both groups gained from pre-test and post-test were compared by means of t-test analysis to see whether or not any changes happened regarding their speaking fluency.

\section{Results and Discussion}

The results of the present study shown in appendix II are in line with the studies conducted by Brinton and Gaskill (1978), Cauldwell (1996), and Mackenzie (1997) regarding the effect of exposure to mass media on improving different language skills. Accordingly, the present study proved that greater exposure to mass media news can improve speaking fluency. The reason behind this might be that the recycling feature of vocabulary used in TV news and the lack of inappropriate pausing, which is fluency of speech, could help the participants in group one to improve their speaking fluency to a significant extent. 
The results of the study challenges and rejects Chambers' ideas (1997) that speaking fluency is acquired naturally during the period of language learning and cannot be improved through exposure to fluent speeches.

\section{Conclusion}

Those elements in TV news which make a particular news item suitable pedagogical authentic material for the second language classroom can be considered as follow.

First, universal exogenous and endogenous contexts are more accessible and understandable to language learners than specialized exogenous contexts, which may require more background knowledge and schema building. While endogenous contexts require little or no prior knowledge, these kinds of TV news stories tend to be less common. Universal exogenous contexts also require prior knowledge, but it is a kind of prior knowledge that language learners can be expected to already have, even though they may not have the vocabulary to express that knowledge. Questionnaires are a good way of monitoring whether students have the expected prior knowledge of universal topics such as studying, working, sleeping, etc.

Second is the issue of criteria in linguistic difficulty. Intensive listening fulfills students' needs to work on bottom-up processing difficulties and balanced top-down approaches to listening comprehension. Redundancy of input is an important aspect in selecting appropriate authentic material and increased redundancy of input is often found in news stories.

It should be noted here that this paper tried to help the teachers in the selection of appropriate TV news material for the second language classroom through providing empirical evidence of the effectiveness of TV news in improving speaking proficiency.

\section{References}

Baker, N. (1996). Using the TV news in the EFL classroom. Zielsprache, 26(2): 30-33.

Bell, A. (1991). The Language of News Media. Language in Society, 16. Oxford: Blackwell.

Brinton, D. \& Gaskill, W. (1987). Using news broadcasts in the ESL/EFL classroom. TESOL Quarterly, 12(4), 403-413. [-15-]

Berber, S. A. (1997). Proficiency and comprehension of television news in a foreign language. Revista de Documentacao de Estudos em Linguistica Teorica e Aplicada (D.E.L.T.A.), 13(2): 177-190.

Brown, G. (1995). Dimensions of difficulty in listening comprehension. In D. J. Mendelsohn, \&

Cauldwell, R.T. (1996). Direct encounters with fast speech on CD-Audio to teach listening. System, 24(4), 521-528.

Chaudron, C. (1983). Simplification of input: Topic and reinstatements and their effects on L2 learners' recognition and recall. TESOL Quarterly, 17(3), 437-458.

Chiang, C. S. \& Dunkel, P. (1992). The effect of speech modification, prior knowledge and listening proficiency on EFL lecture learning. TESOL Quarterly, 26(2), 345-74.

Cooper, R. (1996). Comprehending the Genre of the Television News Report. TESOL Matters 6(5), 10.

Couch, P., DiLeo, J. and Downey, M. (1999). Developing a media news course. Paper presented at the TESOL National Convention, New York.

Freeman, D. (1998). Doing teacher-research: From inquiry to understanding. Boston: Heinle \& Heinle.

Gruba, P. (1997). Exploring digital video material. In R. Debski, J. Gassin, \& M. Smith (Eds.), Language Learning Through Social Computing (pp. 109-140). Parkville Vic: Applied Linguistics Association of Australia.

Joiner, E. G. (1990). Choosing and using videotext. Foreign Language Annals, 23, 53-64.

Mackenzie, A. S. (1997). Using CNN News Video in the EFL Classroom. The Internet TESL Journal, 3 (2). Available at: http://www.aitwech.ac.jp/ iteslj/,.Accessed February 8, 2006.

Meinhof, U. (1998). Language Learning in the Age of Satellite Television. Oxford: Oxford University Press.

Poon, A. (1992). Action research: A study on using TV news to improve listening proficiency. Research Report, 14: $1-70$.

Rubin, J. (1994). A Review of Second Language Listening Comprehension Research. Modern Language Journal, 78(2), 199-221.

Rumelhart, D. E. (1980). Schemata: The building blocks of cognition. In R.J. Spiro, B. Bruce, \& W. Brewer (Eds.), Theoretical Issues in Listening Comprehension (pp. 99-135). Hillsdale, N.J.: Lawrence Erlbaum Associates. 
Shohamy E. \& Inbar, O. (1991). Validation of listening comprehension tests: The effect of text and question type. Language Testing, 8, 23-40.

Stempleski, S \& Arcario, P. (Eds.). (1992); Video in second language teaching: Using, selecting, and producing video for the classroom. Alexandria, VA: TESOL

Weaver, C. (1994). Reading Process and Practice. Portsmouth, NH: Heineman.

Wetzel, C. D., Radtke, P. H. \& Stern, H. W. (1994). Instructional effectiveness of video media. Hillsdale, NJ: Lawrence Erlbaum Associates.

Wodak, R. (1987). “And where is Lebanon?” A socio-psycholinguistic investigation comprehension and intelligibility of news. Text, 7(4), 377-410.

\section{Appendix I}

The Sample Checklist for Measuring Communicative Abilities:

\section{Scale I- Fluency:}

$\square$ 5- Speaks fluently.

$\square$ 4- Speaks with near-native like fluency, pauses and hesitations do not interfer with comprehension

$\square$ 3- Speaks with occasional hesitations.

$\square$ 2- Speaks hesitantly and slowly because of rephrasing and searching for words.

$\square$ 1- Speaks in single word and short patterns, unable to make connected sentences.

\section{Scale II- Comprehension:}

$\square$ 5- Understands academic discourse without difficulty.

$\square$ 4- Understands most spoken language except for very colloquial speech.

$\square$ 3- Understands academic discourse with repetitions, rephrasing, and clarification.

$\square$ 2- Understands simple sentences, words; requires repetitions, slower than normal speech.

1-Understands very little or no English.

\section{Scale III- Communication:}

$\square$ 5- Communicates competently in social academic settings.

$\square$ 4- Speaks fluently in a social academic settings, errors do not interfere with meaning.

$\square$ 3- Initiates and sustains conversation, exhibits self confidence in social situations.

$\square$ 2- Begins to communicate for personal and survival needs.

1- Almost unable to communicate.

\section{Scale IV-Vocabulary:}

5- Uses extensive vocabulary in any domain appropriately.

$\square$ 4- Uses varied vocabulary to discuss general topics and in special interests.

$\square$ 3- Uses academic vocabulary, some word usage inappropriate, slightly damages the message.

$\square$ 2- Uses limited vocabulary, constant use of one word.

$\square$ 1- Inadequate basic vocabulary.

\section{Scale V-Structure:}

5- Masters a variety of grammatical structures, almost no error.

$\square$ 4- Occasional grammatical errors but no problem with understanding.

$\square$ 3- Uses some complex sentences but lacks control over irregular forms.

$\square$ 2- Uses predominantly present tense verbs, constant errors interfere with understanding.

$\square$ 1. Severe errors make understanding completely impossible. 


\section{Scale VI- Accent:}

5- Acceptable pronunciation, with few traces of foreign accent.

$\square$ 4- Speaks with few phonemic errors, but almost intelligible pronunciation.

3- Occasional errors necessitate attentive listening.

$\square$ 2- Constant phonemic errors make understanding extremely hard.

$\square$ 1- Severe problems make understanding almost impossible.

Appendix II

Descriptive statistics related to group one pretest and posttest results

\begin{tabular}{|c|c|c|c|c|}
\hline Groups & $\mathrm{N}$ & MEAN & $\mathrm{SD}$ & $\mathrm{t}$-test \\
\hline Group one pretest & 30 & 2.13 & .50 & -4.253 \\
\hline Group one posttest & 30 & 2.61 & .46 & \\
\hline
\end{tabular}

T-observed $=-4.253$

T-critical $=1.671$

T-observed bigger than t-critical

Descriptive statistics related to group two pretest and posttest results

T-observed $=-0.235$

\begin{tabular}{|c|c|c|c|c|}
\hline Groups & $\mathrm{N}$ & MEAN & $\mathrm{SD}$ & t-test \\
\hline Group two pretest & 30 & 1.96 & .58 & ${ }^{0} 0.235$ \\
\hline Group two posttest & 30 & 2.00 & .41 & \\
\hline
\end{tabular}

T-critical $=1.671$

T-observed smaller than t-critical 